\title{
Impact of Tourism of Off Road Driving on Vegetation Biomass, a Case Study of Masai Mara National Reserve, Narok, Kenya
}

\author{
Medani P. Bhandari \\ PhD, Professor, Akamai University, Hilo, HI. USA; Sumy State University, Ukraine
}

\begin{abstract}
This paper summarizes the arguments and counterarguments within the scientific discussion on the issue of tourist vehicles negative impacts on vegetation biomass, structure, soil infiltration and sensitivity through Off the Road Drive to have closer view of the big five-wildlife of Masai Mara National Reserve, Narok, Kenya. Tourism has been considered as eco-friendly and sustainable business in the contemporary world. Tourists can enjoy the nature and culture and can learn about roles of various ecosystems and biodiversity as well as the cultural heritage of biophysical and socio-cultural environment. In recent decades, the national parks have been considered major attractions to national and international visitors, who love to see the wonder of the wilderness (wildlife, biodiversity, natural and cultural heritage). Through such tourism, the government and local as well as visitor get mutual benefit. However, there is always pros and cons of any activity, if such activities are not managed properly. The main purpose of the research is to show, how tourists willingness (tours operators motive to make tourist happy) to have closer look of big five (African elephant, lion, leopard, Cape buffalo, and rhinoceros) leads off-road driving and how off-road driving can damage the savanna grass ecosystem of Masai Mara ecosystem. Systematization literary sources and approaches for solving the problem is only possible, when such off-road driving is banned. The area where off-road driving is banned since last eight years indicates that damaged area can be improved, however, duration of compacted soil to be normal may take several years. The relevance of the decision of this scientific problem is that off-road driving has negative impact on both fauna and flora. Investigation of the topic Impact of Tourism of Off Road Driving on Vegetation Biomass in the paper is carried out in the following logical sequence: The paper is based on experimental research design and ground truthing. Methodological tools of the research methods were transects approach for the biomass sampling from various sample sites generated randomly and vegetation cover percentages, grass species composition, species sensitivity were measured using appropriate tools. Similarly, surface sealing, soil texture, soil compaction, and water infiltration were measured and compared in the areas where offroad driving was going on (when research was conducted), off-road driving was closed since last one or two years and eight years or more. The object of research is the chosen by researchers own interests. The paper presents the results of an empirical analysis, which showed that different observations and measurements showed that off-road driving has strongly (negative) significant impact, which has decreased vegetation biomass. Compared to ORD impact, other environmental factors do not have a significant impact. The results also showed that management (area closure for ORD) has a significant positive impact on the improvement of the damaged area. However, it was found that the vegetation recovery after the closure for ORD was very slow. The research empirically confirms and theoretically proves that off-road driving has negative impact on soil and vegetation. The results of the research can be useful for the proper management of national parks and wildlife reserves as well gives new insights to the park tourism industry.
\end{abstract}

Keywords: tourism, off road driving, biomass, impact, closed and open areas.

JEL Classification: L83.

(C) The Author, 2018. This article is published with open access at Sumy State University.

\section{Introduction}

Off road driving (ORD) in the national park has been defined as driving outside the road to look for wild animals in the reserve. It includes any vehicle not driving along the road or designated path (Conservation Environment, 1988).

The scientific community has not ignored the problems associated with off road vehicles. Many studies have been conducted by geologists, engineers, ecologists, sociologists, anthropologists, psychologists, and other professionals who have investigated off road vehicle problems (McCool, 1981). Many writers have also focused on off-road driving problems in the national park and recreationally valued areas, and they have also 
tried to measure the degree of damage. The scientific communities have also grouped the problem of ORD into behavioural, administrative, environmental, economic, safety, resource, facility needs, technological, and land use conflict (McCool, 1981). However, millions of people participate in recreational activities (Sheridan, 1979), but there is not sufficient systematic research into it in the case of national reserves. Many questions and comments with respect to ORD research are necessary. Available literatures do not cover many of the impacts; even so, Baldwin and Stoddard (1973) have provided a popular review of ORD impacts and regulations. Likewise, Brander (1974) has reviewed ecological effects while Bury (1978) has studied the effect on snow wildlife. Many scientists have also tried to evaluate the impact on soil, focusing mainly on soil compaction, vegetation damage, and the change of infiltration rate, erosion, wildlife, and ecological setting (Bhandari, 1998, 2000).

Many scientists have found the off-road driving very problematic and harmful. Several National Parks authorities of United States are closely working to find out the degree of damage by the off-road vehicles. Minnesotans for Responsible Recreation, December 1999, has concluded that Off road vehicles are problematic and generate conflicts between other visitors and also harm the environment, forest, parks, trails, and waterways. The photographic survey, conducted by the research team of Minnesota, found the significant impact on forest, wildlife areas, and wetlands and labelled off road vehicle driving "all is not well". Michael Sawyer at al. (2005) found that off road vehicles have negative impacts to the protected areas. They found negative impacts on all wildlife, vegetation, birds, and even for various fish species. Belnap (2002), identified that Off-road vehicle damages land cover and to soil lichens and disturbs the soil nitrogen cycle. The degree of negative impact can be found in all type of soil; however, the intensity can be different according to soil type, and State Environmental Resource Center, Madison, Wisconsin- (2003), declared that ORVs ruins wildlife habitat creating more tracks which alternately convert to the permanent like roads. ORVs damages vegetation increases soil compaction and pollute water, soil and air. ORV destroys nitrogen formation in soil and damages the nutrient cycle of the land on the basis of various research done by scientists. Like wise Illinois Action Project (2001-2005) document concluded that ORV has negative impact on human health. Normally ORVs produce 81-111 decibels sound which can increase heart rate, blood pressure and in long run it impact can be more severe. Same system works to the wildlife also. It can change wildlife moving pattern, can lead behavioural change. Georgia Forest-watch study (2005) found; Illegal ORV use affects the forest, by increasing sedimentation in aquatic and riparian areas, modifies animal behaviour, increases animal mortality, spreads exotic species, fragments the forest, increases noise and air pollution and alters the chemical and physical environment and Backcountry Hunters and Anglers (2005), figured out that Off Road Vehicle damaged ecology of many places of American wild-land. It has helped to increase the sedimentation of valuable riparian areas and fragmented wildlife habitat.

Davidson (2005), documented that Off-road driving can evict endemic vegetation by introducing noxious species. Can lead soil erosion, pollute surface water and can help to wash the top soil at fragile land. Further can change or destroy wildlife migration route. Further Siskiyou Wild Rivers Campaign-2005, states "Off-road vehicles (ORVs) damage sensitive plant communities, wildlife habitat and riparian areas through erosion, soil compaction, plant mortality, noise and pollution. ORVs are also a main vector for non-native, invasive plants and diseases. A single reckless ORV rider can, in a single afternoon, destroy a rare wildflower community that may have existed in the same area for millions of years".

Most of the available research reveals the negative impacts of off-road driving and are based on developed world situation. Published scientific articles clearly state the damage is significant. Some of the scientific publications are based on experimental field research, or comparison between controlled situation and uncontrolled situation. However, the lacking point is experiment on the real field, where off road driving is not for fun of driving nor to the driver nor the people who are on the van. Off-road driving is in use and in practice more than 50 years, to see the beauty of wildlife in situ situation. Every year thousands of tourists visit such a wonder of nature in Asia, Africa, Latin America and also pacific continent and Europe and North America.

Situation of developed world is different rules and regulations are strict and while visiting natural wander, visitor behaviour is not same as they act while they are in the developing world. Most important is that, most of the tourists in the developed world are from the people from the developed world. Rarely any tourist from the poor developing country visits developed world for fun and go to see the natural wonder; except the students from the developing world who are studying in developed world. Inter continental tourist flow is common, a developing country people can visit another developing country and can manage herself or himself. Tourists in the developing world are mixed, whatever is the purpose. In general understanding in the developing world is different. Normal people think tourist means "people from the developed world". Their treatment 
is not same as they do to the native people. Local tourist operators think developed countries tourist is a tree of dollar, and need to grasp dollar by making them happy. The reason is poor economic situation where a single box means something big, some achievement of the day. This paper is an example of how Off-Road Vehicles can be responsible to destroy vegetation surface and how severe can be the impact of Off-Road Driving.

\section{Objective}

Major objective of this research was to assess the impact of off road driving on the reserve and identify the degree of damage and specific objectives were, to study the recovery of the vegetation after closure of damaged areas, and to study the possible reasons for the observed lack of vegetation recovery. To meet the objective following research questions were tried to answer. What is the density of off road tracks? What is the impact of ORD on soil, biomass and species composition? What is the recovery of vegetation after closer of damaged areas? What is the possible reason for the observed lack of vegetation recovery?

This exemplary research was carried out on the Masai Mara National Reserve, Narok, Kenya where, fortunately, we have areas where, (i) still off-road driving is continue, (ii) off road driving is closed since last one year and (iii) area where off road driving is closed since last eight years. We have naturally controlled situation and open area for the evaluation of impact of off road driving in natural settings. We have examined the mainly vegetation damage by the off-road driving and explored the degree of damage, using available scientific tool and techniques.

\section{Study Area}

The Masai Mara National Reserve lies in Narok district of Kenya, South-Western Kenya bordering Serengeti National Park, on the Tanzania border. It lies between latitudes $1^{0}, 13^{\prime}$ and $1^{0}, 1^{0}, 45^{\prime \prime}$ south and between longitudes $34^{0} .45^{\prime}$ and $35^{0} .25^{\prime \prime}$ east between: 1,500-2,170 m altitude. It forms the northern portion of the Serengeti Mara System that covers an area of 40,350 square kilometers (Burney, 1980), of which the Mara National Reserve comprises $1,673 \mathrm{~km}^{2}$. The Masai Mara Reserve is surrounded by the group ranches and is divided by Mara River. This park was established as world heritage site in 1989. The main purpose of the establishment of this park was to protect the existing wildlife.

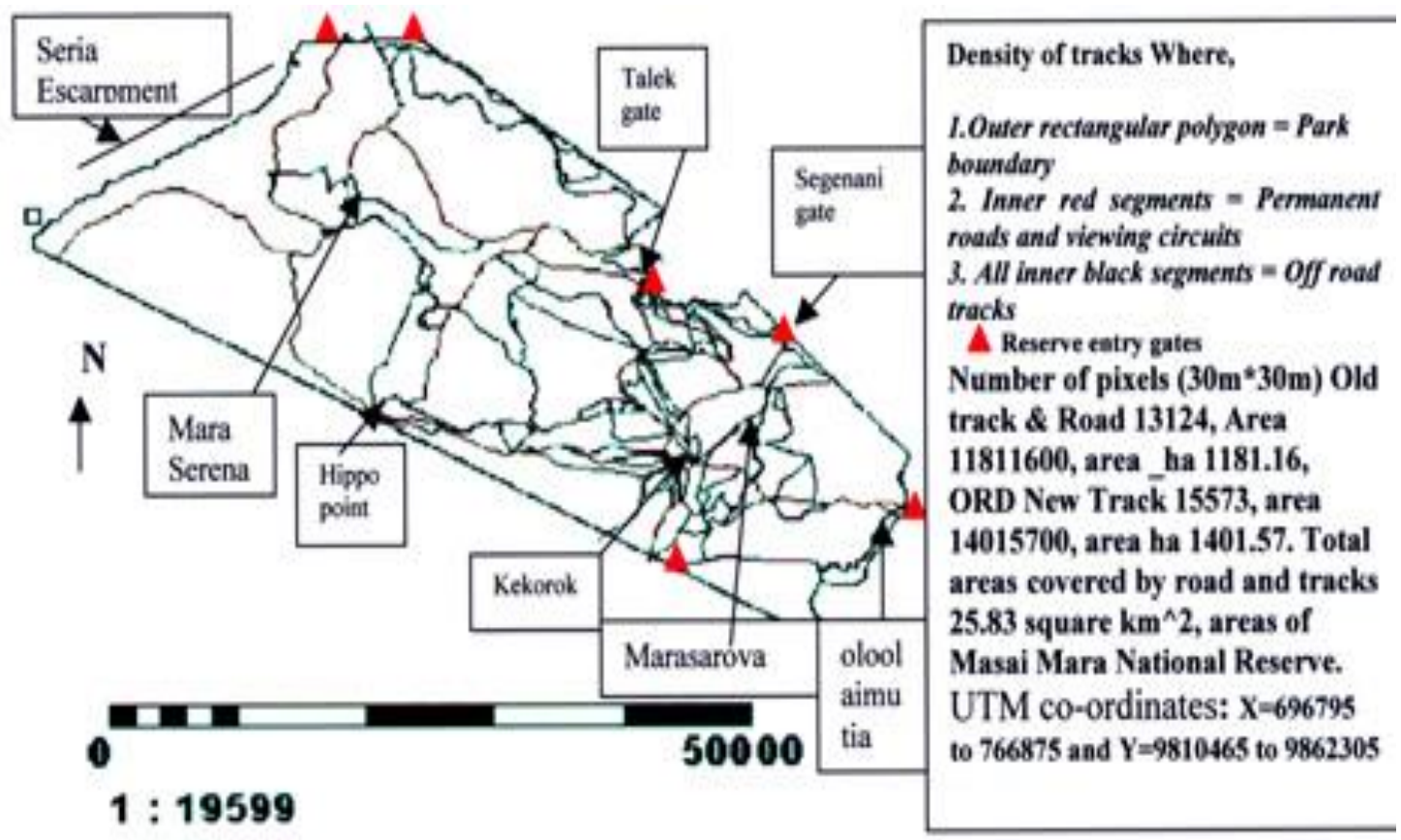

Figure 1. The main road and wider off-road tracks during image processing

ORD Map source: map reveals the damaged locations (Bhandari, 1998).

In the image it is possible to visualize the main road and wider off-road tracks during image processing and to differentiate the areas where biomass is high or low. To some extent it is also possible to locate the ORD tracks in the lower grass covered areas maps. However, for the high grass covered area the Aerial photo or the Hyperspectral image and field observation is needed. Map is based on the Landsat TM satellite image, topological 
maps, and tourist maps provided by Reserve. This map shows the track density in the park as well as general overview of ORD impact on the reserve. Calculated map reveals road and off-road tracks has covered 25.83 square kilometre land" (map and texts on italics was adopted from Bhandari, 2014: 474).

Masai Mara National Reserve is one of the most visited reserve in the world. The tourist inflow in one hand produces the economic benefit; on the other hand, it may bring many problems. One of them is off road driving in the park (Bhandari, 1998).

UTM X=748988.25

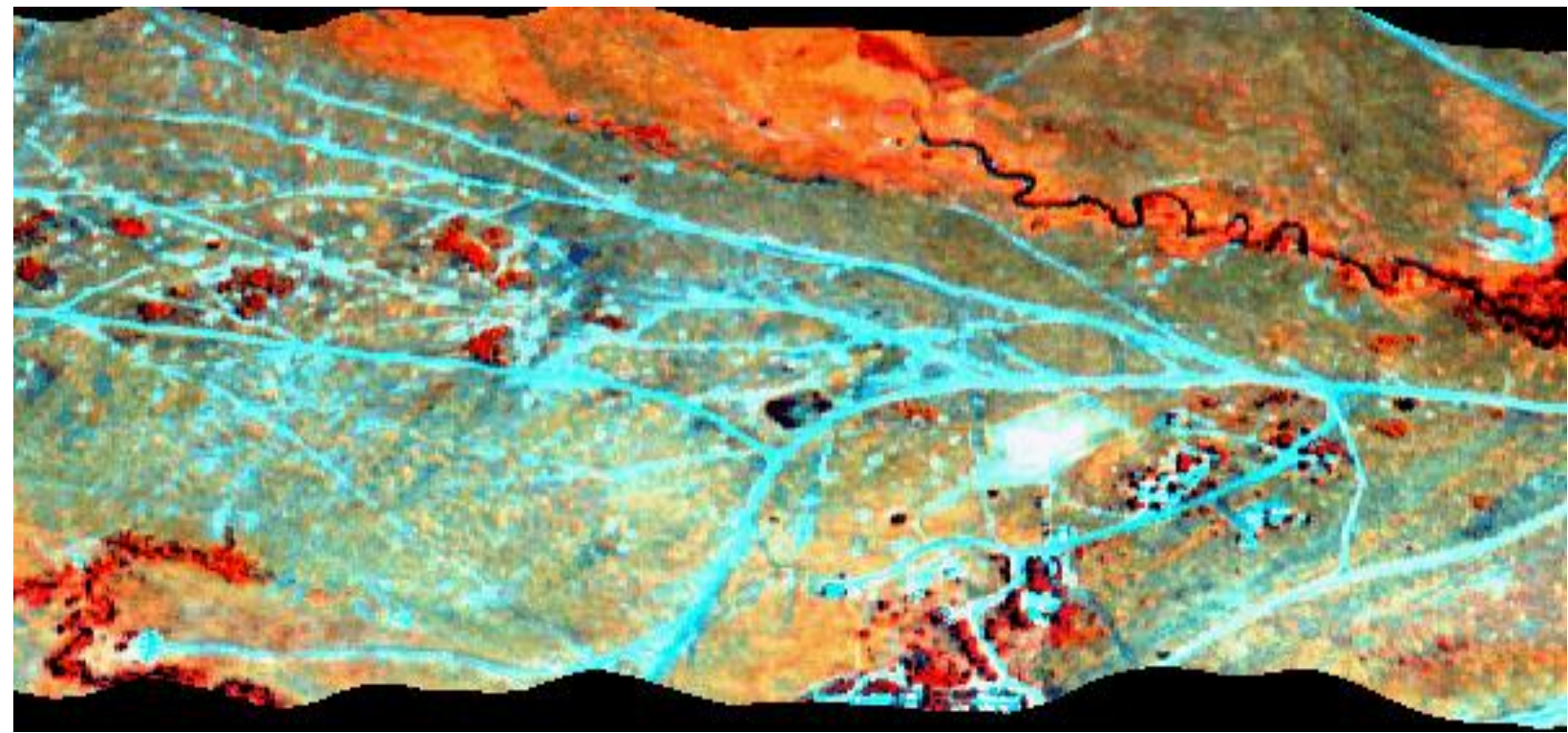

Figure 2. Off-Road Drive Map showing severe damages

UTM X=747188.

Image cited from Bhandari, 1998 and 2002.

Hyperspectral radar image of Kekorok area in Masai Mara Nation Reserve.

Image shows the ORD impact on the park.

Where, Dark red area $=$ forest, Yellow $=$ bush land, Yellowish blue $\&$ green $=$ grassland,

Sky blue $\&$ white $=$ Roads, tracks $\&$ bare areas .

\section{Research method}

Research is mainly based on secondary data provided by the expert from Kenya (2004-2012) and field research of (1998, 2000 and 2003). Maps are used from Bhandari M. (2002). Tourism raised problem on Masai Mara National Reserve, Narok Kenya, Mountain Forum online library and Walpole at al/ (2003), "Wildlife and People: Conflict and Conservation in Masai Mara, Kenya" IIED, UK, and Mara Count (2002).

Requests for the data were posted to the mountain forum list serve and we received 25 responses, requests were also published on the weakly online journal Forest Information Update Vol. 6, No. 25, 20 June 2005, and additional requests were also posted at http://home.comcast.net/ gyde/index.html and on the mailing list. Messages regarding the garbage problem within the national parks, protected areas, and zoos were also posted at the International Training Centre, Durell Wildlife Preservation Trust, and the U.K. ITC-list serve. A feedback from all concerned people is incorporated in this research. General tourist data flow from various years of Kenya and Masai Mara were obtained from the publications of the Central Bureau of Statistics of Kenya, Kenyalogy, Kenya Wildlife Service, and United Nation Environment Program.

Off road driving impacts are examined in terms of vegetation damage such as differences on biomass by the off-road vehicles used area and not used area. We also examined the area where now off-road vehicles are not in use, but used to one year and eight years before. Further, we have examined the vehicles two-wheel tracks damage situation in particular and the impact in between the two tracks and distance how far a off road vehicle can damage where wheel did not roll directly but left the side effect. 


\section{Data collection techniques}

\section{Transects}

The transect approach is very popular in vegetation research. A transect is a line along which samples of vegetation are taken. Transects are usually set up deliberately cross-areas where there are rapid changes in vegetation and marked environmental gradients. Most transects are thus biased in their location, although it is possible to locate the start and end of a transect at random and then take samples along the line connecting the two points. This method is widespread in the field of off road driving assessment (Hosier \& Eaton, 1980, Bruman \& Fuller, 1977). Transect methods of data collection were used to assess the impacts of off the road driving.

\section{Layout of sampling sites}

At every site we established four transects perpendicular to the track. Seven plots were located along every transact. The first, second, sixth and seventh plots were located outside the track and were considered to represent the situation of unaffected vegetation. Plots three and five were located on the track, while the fourth plot was located in the middle of the track.

Regarding vegetation damage, we have taken major biophysical measurements to see the degree of impacts on following parameters:

Off the road driving (ORD) impact on biomass: To test the impact of ORD, we have taken the biomass sampling from various sample sites generated randomly and locations were noted by using Global Positioning System (GPS). Biomass was clipped to ground level and weighed in the field to the nearest gram.

Estimation of vegetation cover percentage: Like biomass weight, vegetation cover percentages were also sampled to examine the impact of off road driving.

Species composition identification: Each existing species was noted and its percentages of appearance in each site were noted. In each site, seven observations were made.

Estimation of vegetation damage: Visual estimation was made using expert knowledge.

Impact of off road driving on species composition: Species composition data were collected along the transects, perpendicular to tracks: sample not affected by ORD (outside track), sample moderately affected (middle of the track) sample severely affected (inside the track).

Species sensitivity for off road driving: Very common vegetation (grass) species data were collected along the transects, perpendicular to tracks: sample not affected by ORD (outside track), sample moderately affected (middle of the track) sample severely affected (inside the track).

Surface sealing and biomass: Ground (soil) surface situation were measured using penetrometer.

Soil Texture and biomass: Biomass situation were also tested on the basis of soil texture.

Soil moisture on top and sub soil VS biomass: Used expert knowledge to note the situation.

Measurement of soil compaction: Soil compaction data were collected using penetrometer. Penetrometer reading were noted on kilohertz unit (readings on the meter). Penetrometer was pushed in to the surface of the ground in the track, middle of the tracks and out of the track until the mark of penetrometer head was covered / entered and the pressure was read on the scale.

Masurements of infiltration: The test was done to see the differences in soil strength between the tracks, middle of the tracks and out of the tracks. Iron infiltration rings were used to carry out infiltration measurements. Rings were pushed two centimetres in the soil correctly and adjusted to avoid the water loss by using a hammer. Five measurements were taken. In each site in the first track, middle of the tracks, in the second track and outside of both first and second tracks, infiltration rings were established. In each of the ring four centimetres of water was filled in and time was noted.

The more details explanation with sketches and symbols are presented on each parameter description. Acquired data are analyzed using EXCEL, SYSTAT and SPSS software. Both parametric and non- parametric statistics are used to draw the conclusions. 
Appropriate citation is listed within the bibliography; however, if we missed anyone we would like to request the appropriate authority forgive our mistakes.

\section{Result and discussion}

\section{Measurement of biomass and biomass clipping}

The damage to vegetation cover due to the off-road vehicle is very common in the reserve. Vehicle tracks are everywhere and damaged and undamaged areas are clearly visible. The reserve is easily accessible. Only a few gullies and rivers interfere with cross-country vehicle movements. Repeated off road driving has resulted in localized degradation of grass and development of multiple tracks, which destroy the naturalness of affected areas. Vegetation damage is proportional to vehicle weight (Radforth, 1973; Ayers et al., 1990).

The impact of off road driving on vegetation biomass was studied in the following way: During the field work we collected biomass data for seven $0.09 \mathrm{~m}^{2}$ sites located along transects perpendicular to the track. Biomass was clipped to ground level and weighed in the field to the nearest gram. This process was repeated four times within a fifty-meter distance in the site. In this way, twenty measurements in each location were collected. Total off-road site sampling were 164 but for grouping purposes according to the area closed only 48 sites were considered to see the biomass weight variation. The rest of the sample is used to see other impact in this study. Total number of measurement to see the biomass was $48 * 5 * 4=960$. Biomass damaged due to the vehicle was measured in $0.09 \mathrm{~m}^{2}$ using rings.

Collected data were processed first in spreadsheet. Four preliminary analyses were made. The five samples were converted to three main group inside the track, middle of the tracks and out of the track by averaging two out and in samples accordingly. In the off-road driving areas, biomass is different in the off road driven tracks, middle of the two tracks and out of the tracks. Off road drive area has various impacts and these areas are fully affected. Off the road drive areas are not similar to other areas where off road driving never took place and within the off-road drive area biomass is not equal in the track, middle of the two tracks and just outside of the track.

To examine the alternate hypothesis, field survey and biomass weight measurements were carried out. Sample plots were identified using different methods. Using random number generator first plots were identified and samples were collected wherever sample points falls. In this type of sampling, in 120 sample 41 samples were in the off the road tracks. But due to the lack of sufficient number of equipment's biomass samples were not collected in all areas. After this, the random cluster sampling transact method was applied and a total seventyfive off road track samples were collected.

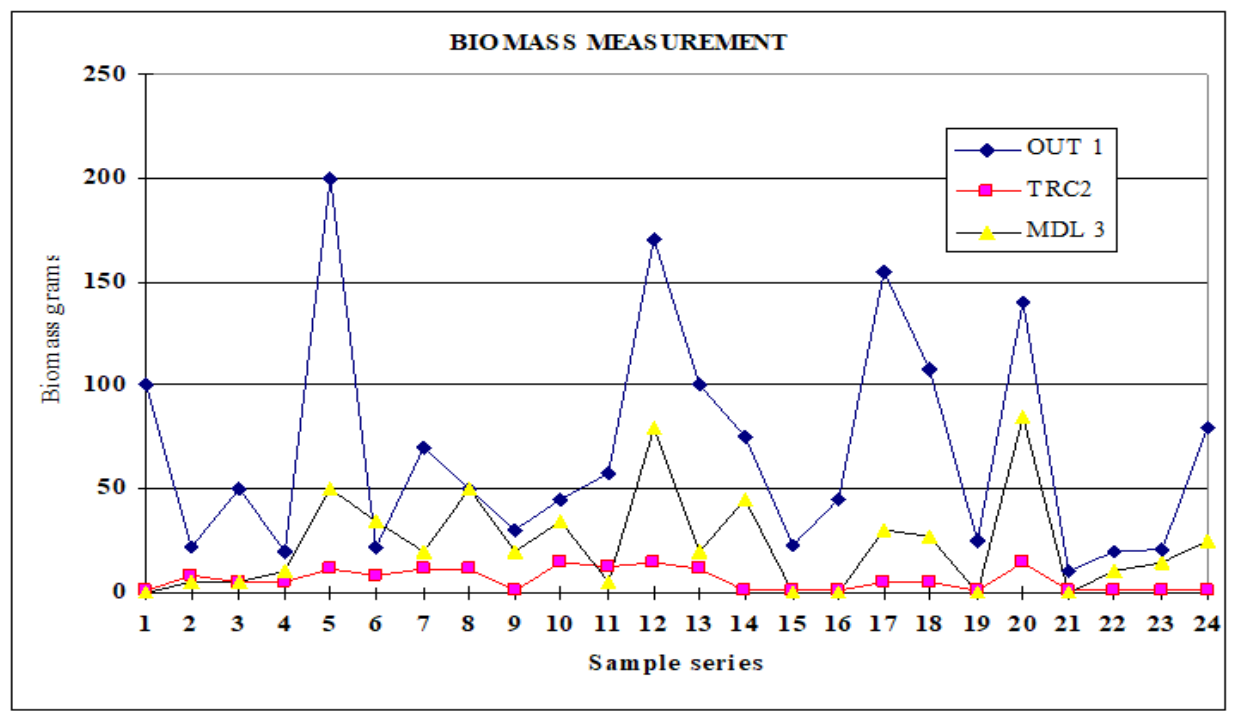

Figure 3. Biomass measurement in various sites

Figure 3 shows the biomass distribution in relation to sample locations; where each twenty-four sites out of the tracks biomass is higher than middle of the track; and all sites inside the tracks biomass very close to zero. The graph also reveals the species sensitivity as well as overall situation of vegetation damage in the reserve due off-road vehicles. 


\section{Off the road driving (ORD) impact on biomass}

First, it was tested whether there was a difference in biomass between tracks and the areas which were not affected by tracks. Three categories of biomass observation data were collected along transects perpendicular to the tracks: sites not affected by ORD (outside of the track), sites moderately affected by ORD (middle of the track) and sites severely affected by ORD (inside the track). The differences were tested in the median biomass of three categories, using the Kruskal-Wallis test since data were not normally distributed.

We tested the following hypotheses:

H0: $\Pi(\mathrm{i})=\Pi(\mathrm{m})=\prod(\mathrm{o})$, Ha: one of the categories differed from the others in median biomass (see chapter 3.7). The data revealed a significant difference between the three positions along the transects in median biomass (Kruskal-Wallis; Chi-square $=32.4 ; \mathrm{p}<0.0001$ ).

In the above-mentioned analysis all the data, we pooled together irrespective of management status. In further analysis, we tested for each of these ORDs whether there was an impact of management status on the vegetation biomass. The null hypothesis stated that the median biomass was equal for all management categories be it not protected or protected for 1 or 8 years respectively.

The Kruskal-Wallis test revealed that there was significant difference in vegetation biomass between the management categories in the track (Chi-square $=7.70 ; \mathrm{p}<0.021$ ), in the middle of the track (Chi-square $=59.28$, $\mathrm{P}<0.0005)$, and outside of the track (Chi-square $=54.87, \mathrm{P}<0.0005)$.

These tests indicate that areas which differed in management practice tend to show significant difference in biomass. Figure 4 revels that biomass increases with the duration of closure for all three categories.

The increase of biomass inside the track as well as the middle of the track could be attributed to the closure of these tracks. However, the biomass increases as well outside the tracks. One explanation for this finding could be that, this is the result of incidental off track driving. Vehicles frequently leave the tracks partly to observe animals more closely, partly to avoid muddy parts during the rain and partly for easy drive. An alternative explanation would be that the biomass is higher, because of differences in environmental conditions between the various areas where the tracks were located. The descriptive structure of this research does not allow to determine the cause for this increase of biomass with time of closure.

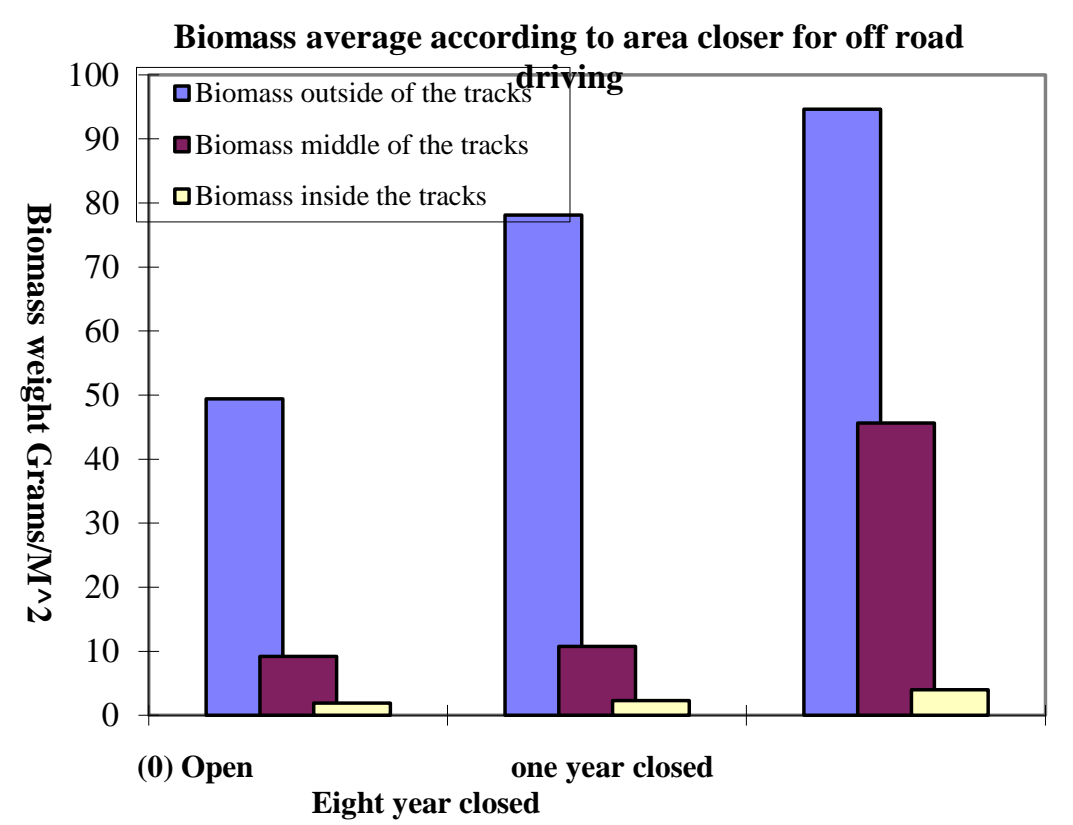

Figure 4. Biomass (kg/ha) in relation to management for the sites on the tracks, middle of the tracks and outside the tracks Where,

$0=$ track currently used by vehicles, 
$1 \& 8=$ tracks closed to traffic for 1 and 8 years respectively, yellow bar show inside the track, red shows the middle of the track and blue bar shows the out of the track's (biomass kilograms per hectors) situation. Chart reveals the Biomass differences in and out of the track and closed and open area variations. In the track biomass is very low representing by the yellow colour and other two are middle and out of the track respectively

\section{Estimation of vegetation cover percentage}

Like biomass weight, vegetation cover percentages were also sampled to examine the impact of off road driving. Species cover percentages were estimated one by one species and all those species' cover percentages were added to get the site percentage. Seven observations were made in each site. Four out of the tracks (1a, $1 \mathrm{~b}, 5 \mathrm{a}$ and $5 \mathrm{~b}$ ) covering both side one each from two tacks (2 and 4) and one from the middle of the track (Figure 5).

$1 \mathrm{a}$

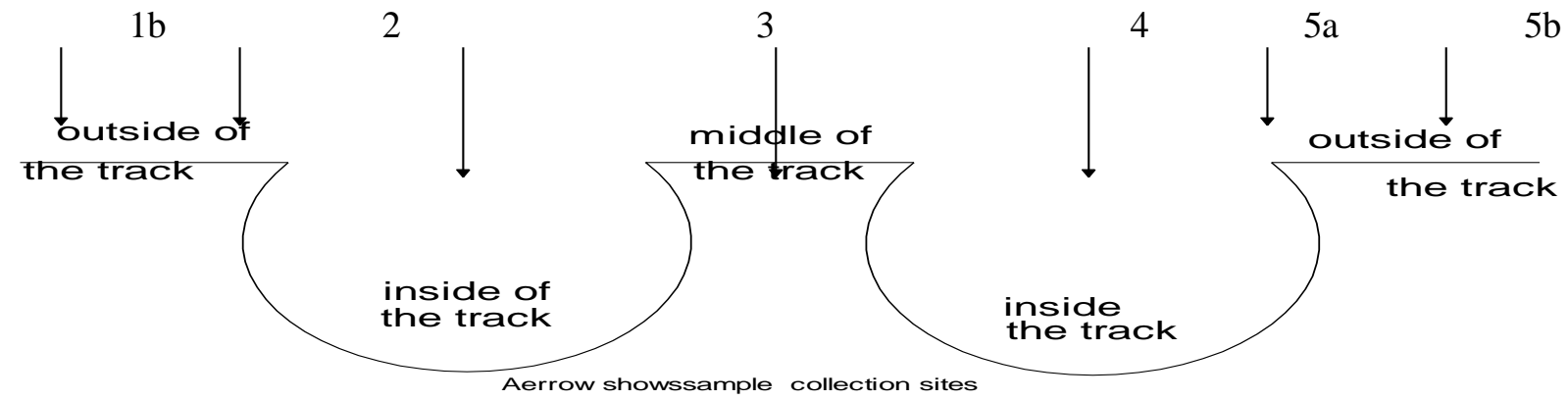

Figure 5. Sampling layout for vegetation cover percentage

\section{Off road driving impact on vegetation, cover percentage}

As it had been discussed in the 4.2.1, it was necessary to analyze the differences whether the vegetation cover percentage differs. It is known that non-parametric statistics, Kruskal-Wallis or Mann-Whitney test can capture the differences among the cases (Skidmore 1997) to see the relation between different categories. There was a significant difference between inside, middle and outside of the track vegetation cover along the transects (Mann-Whitney $u$ test statistic $=9216.000$, chi-square approximation $=143.643$, probability $<0.0005)$.

In the analysis, all data were pooled together irrespective of management status. Further analysis was done to find out whether there was impact of management. The hypothesis was tested. The null hypothesis was rejected and the alternative hypothesis was established, stating that there were significant differences on vegetation cover inside the track and middle of the track among the area open, closed for 1 year and 8 years respectively for ORD (Kruskal-Wallis; inside the track Chi-square $=7.448, \mathrm{p}<0.024$, middle of the track Chisquare $=6.243, p<0.044)$. However, there was no significant differences of vegetation cover percentage in the case of outside track (Chi-square $=1.924, \mathrm{p}>0.4)$.

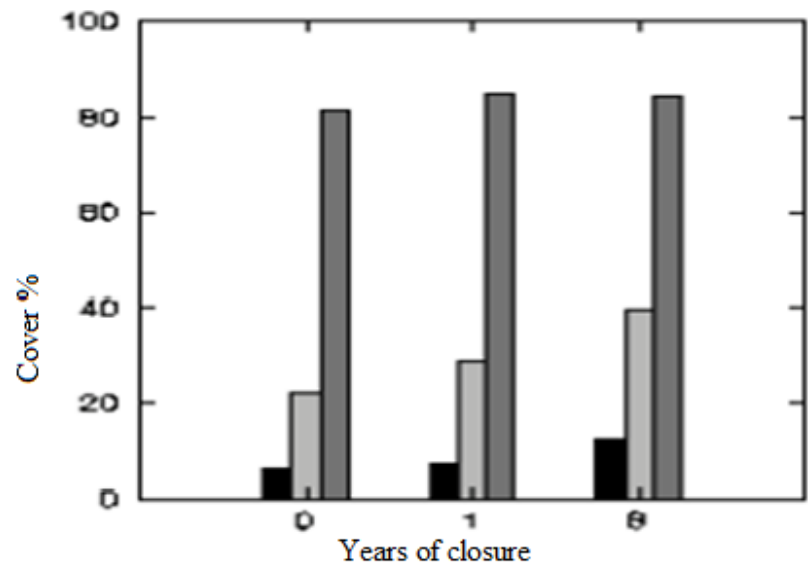

Figure 6. ORD Tracks vegetation

These tests indicate that the management practices of closure the area for ORD have significant impact on the vegetation cover inside the track and middle of the track. 
In figure 6 shows the vegetation cover differentiates according to track and area closure. Black bar show inside the track, grey shows the middle of the track and blackish bar shows the out of the track's (vegetation cover percentage per hectors) situation.

Figure 6 shows the vegetation cover percentage in the track middle of the track and out of the track. Figure also shows the increment of cover percentage in the closer area. $O$ years cover percentage is less than 1 and 8 years but the growth rate of cover percentage is lower as biomass.

\section{Species composition identification}

To examine the species composition, data were collected as cover percentage data (figure 3.1). Each existing species was noted and its percentages of appearance in each site were also noted. In each site seven observations were made. A total of 51 species were recorded in the off road driving open and closed areas.

Table 1 . The following species were used for statistical analysis.

\begin{tabular}{|l|l|}
\hline 1. Themeda triandra & 11 . Cynodon dectilon \\
2. Dichanthium insanlpta & 12 . Cloris gayana \\
3. Aristida adoensis & 13 . Sporobus fibriatis \\
4. Eragrostis raccamosa & 14 . Laudetia kenjerensis \\
5. Eragrostis tennifolia & 15 . Fuerstia africana \\
$6 . \quad$ Digitaria longiflora & 16 . Eragrotis brannii \\
$7 . \quad$ Harpachne schimperi & 17 . Eragrotis exasperta \\
8. Sporobus pyramidalis & 18 . Pennisetum mezianum \\
$9 . \quad$ Microchloa kuutii & 19 . Bacium oboratum \\
10. Indigofera volkensis & 20. Sporobus staptiana \\
\hline Seteria sphacclata & Sida cuncifolia \\
Hypertheria dissoluta & Trugus berterteronium \\
Hypertheria rufa & Oxygonum sinuatum \\
Aristida kenyansis & Penicum species \\
Aerva lanata & Cyperus species \\
Heteropogon contortus & Solanum incanum \\
Brachiaris brizantha & Cloris redican \\
Crossandra velutina & Cloris pycnothrix \\
Crotalaria spinosa & Ruellia paluta \\
Gutenbergia cordifolia & Digiteria abyssinica \\
Eustachys paspuloides & Cycnium tubulosum \\
Digitaria milanjiana & Dichanthium redicum \\
Justicia exigua & Sporobus confinis \\
Polygala stephophera & Lencas species \\
Commelina africana & Cassia mimosoides \\
& Murdania simplex \\
\hline
\end{tabular}

Each of the above species was compared in each case in the track, middle of the tracks and out of the tracks as well as open areas for off the road driving, one year closed and closed eight years before.

It was tested if there was a difference in the species composition between the tracks and the area, which were not affected by tracks. Species composition data were collected along the transects, perpendicular to tracks: sample not affected by ORD (outside track), sample moderately affected (middle of the track) sample severely affected (inside the track). The differences were tested in the median of species composition percentage using Kruskal-Wallis test because data were not normally distributed.

These statistical tests indicate that there was significant impact of ORD on species composition (see appendix for detail). Track species composition was not equal to outside track species composition. Further analysis was also done only considering outside track species composition. However, test showed no difference on species percentage between the areas closed or open (see appendix for detail). So, on the basis of above statistical test, it can be concluded that ORD has significant impact on species composition.

\section{Impact of off road driving on species composition}

It was tested if there was a difference in the species composition between the tracks and the area, which were not affected by tracks. Species composition data were collected along the transects, perpendicular to tracks: sample not affected by ORD (outside track), sample moderately affected (middle of the track) sample severely affected (inside the track). The differences were tested in the median of species composition percentage using Kruskal-Wallis test because data were not normally distributed. 
These statistical tests indicate that there was significant impact of ORD on species composition (see appendix for detail). Track species composition was not equal to outside track species composition. Further analysis was also done only considering outside track species composition. However, test showed no difference on species percentage between the areas closed or open.

\section{SPECIES COMPOSITION PERCENTATE IN THE TRACK AND OUTSIDE THE TRACK}

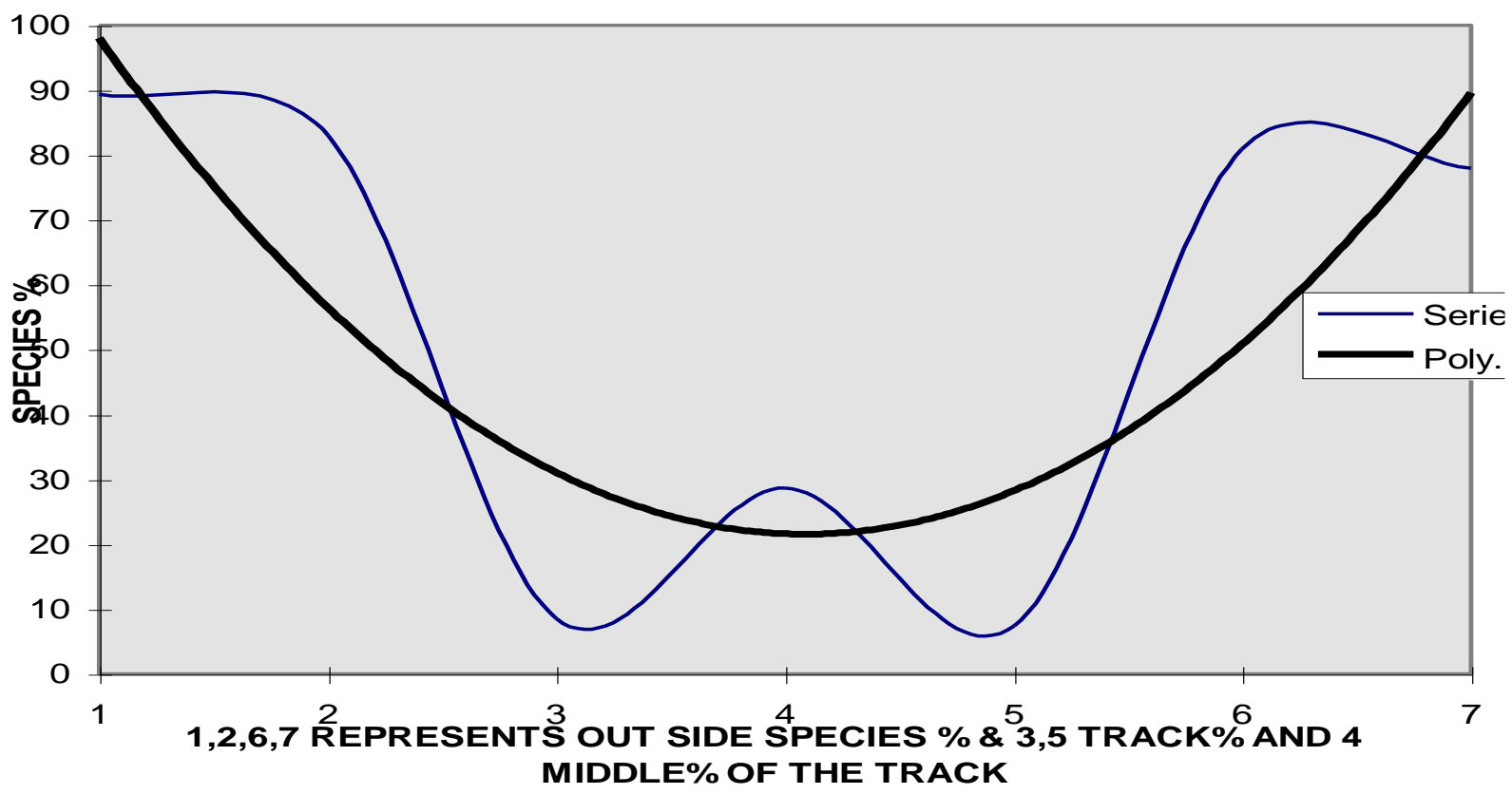

Figure 7. Plants sensitivity with ORD

\section{Species sensitivity for off road driving}

The frequency table shows that all species are sensitive and can not tolerate the pressure of off the road driving (Figure 7). However, the degree of resistant is different. The very common species Themeda triandra is most sensitive species for off road driving. In all observations there is no single Themeda species in the track. In the areas of 8 years of closure instead of the original species new species Eragrostis recamosa, Eragrostis tennfolia, Harpachnne schimperi, Cloris gayana, sporobus fimbriatus, Microchloa kuuthii, Cynoden dactylon and more Eragrostis and Sporobus species are emerging in the track where as in middle and out of the track Themeda species is still dominant.

The data shows most sensitive and least sensitive species as follows:

Table 2. Species frequency in the sample site

\begin{tabular}{|l|c|c|l|c|c|}
\hline \multirow{2}{*}{ Most sensitive } & \multicolumn{2}{|c|}{$\begin{array}{c}\text { Number of time } \\
\text { occurrence }\end{array}$} & & \multicolumn{2}{c|}{$\begin{array}{c}\text { Number of time } \\
\text { occurrence }\end{array}$} \\
\cline { 2 - 4 } & In track & Out track & & In track & Out track \\
\hline 1. Themeda triandra & 0 & 78 & Eragrostis tennifolia & 66 & 62 \\
2. Dichanthium insanlpta & 0 & 54 & Harpachne schimperi & 40 & 44 \\
3. Sporobus pyramidalis & 1 & 62 & Microchloa kuuthii & 14 & 33 \\
4. Dyschoristers redican & 0 & 34 & Cynoden dactylon & 14 & 17 \\
5. Digiteria longiflora & 0 & 30 & Eragrostis recamosa & 10 & 31 \\
6. Pennesteum mezianum & 0 & 27 & Sporobus species & 10 & 30 \\
7. Hypertheria dissoluta & 0 & 22 & Cloris species & 10 & 28 \\
\hline
\end{tabular}

The result shows 0 time's occurrences in the all track situation and 0 recovery after the closure of the area (Table 2). On the base of these results we can conclude that off road driving has strong impact on Themeda triandra. 
THEMEDA TRIANDRA

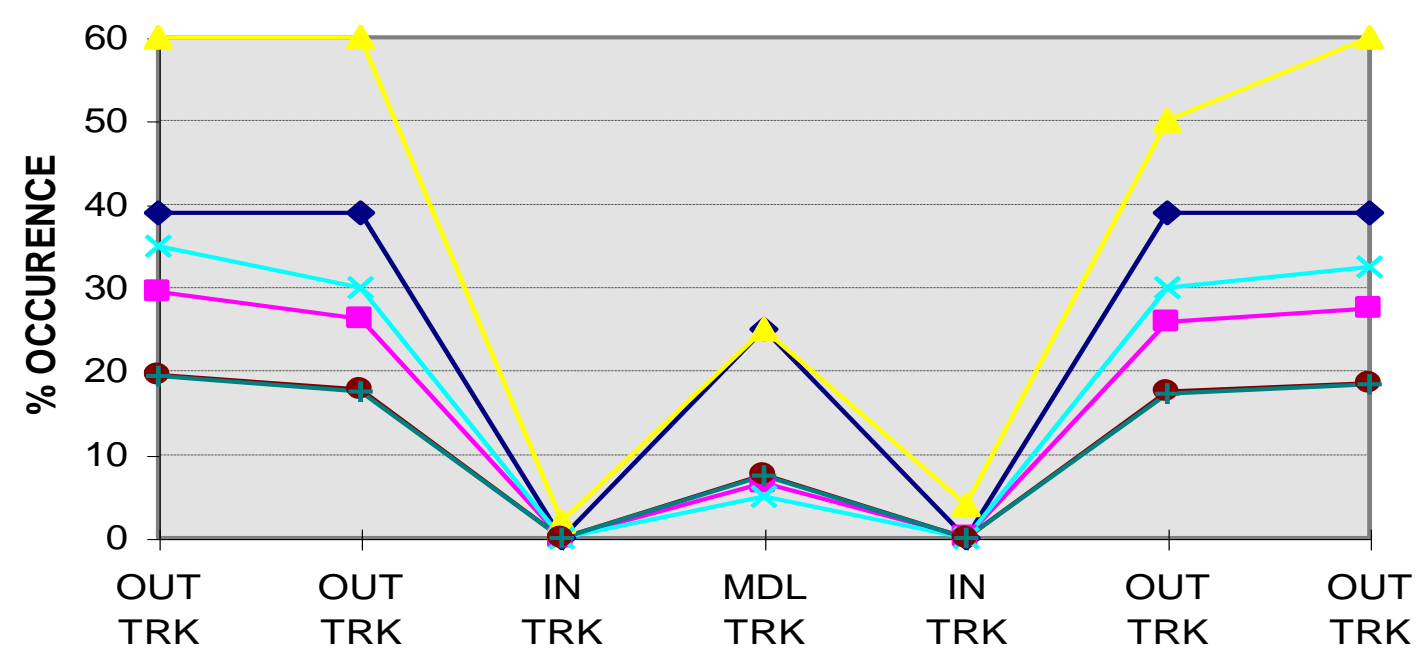

Figure 8. The dominant grass species Themeda Triadra, sensitivity with ORD

Figure 8 shows the sensitivity, where left to right; out side track two meter far from the track, out of the track one meter far from the track; inside the tack, middle of the two tyres; inside the track and again out side track two meter far from the track, out of the track one meter far from the track respectively.

\section{Other possible factors for biomass decrease}

To identify the possible causal factors of biomass degradation the following parameters were also analysed.

i) Surface sealing and biomass:

In the cases of surface sealing, data do not show the normal distribution and sealing information is in class form. Therefore, non-parametric Kruskal-Wallis test is applied to see the impact on biomass. The test shows that there is no difference of biomass in the sealed soil surface and without surface sealed soil. However, sealing showed affects on out of the track biomass. The surface sealing areas biomass and without sealing areas biomass in the outside track is not equal. However, there is no statistically significant difference in the track and middle of the track biomass.

Table 3. Kruskal-Wallis test out put

\begin{tabular}{|l|c|c|}
\hline \multicolumn{1}{|c|}{ Groping variable Surface sealing } & $\begin{array}{c}\text { Test statistics } \\
\text { Chi-square }\end{array}$ & Probability (sig) \\
\hline Biomass in the Track & 2.025 & 0.155 \\
\hline Biomass middle of the Track & 0.012 & 0.914 \\
\hline Biomass out of the Track & 3.883 & $0.049^{*}$ \\
\hline
\end{tabular}

Confidence level (95\%) in 2 degrees of freedom.

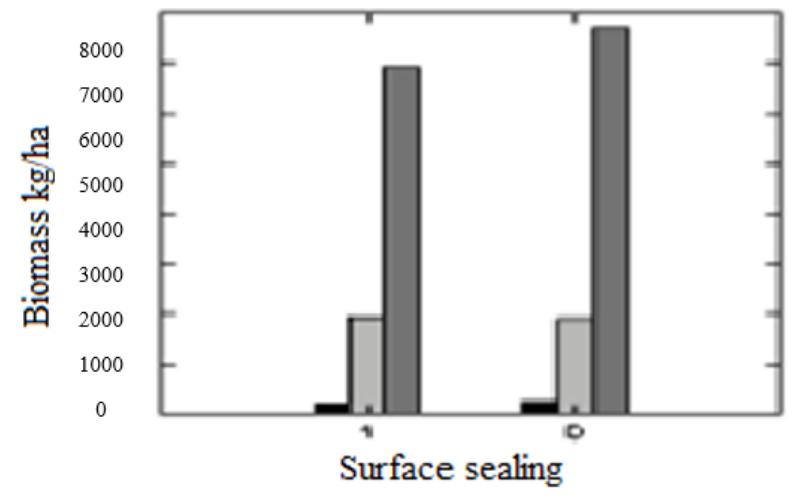

Figure 9. Influence of surface sealing on biomass 
Figure 9 shows ground surface sealing due to ORD.

Where, $0=$ not surface sealing area, $1=$ surface sealing area,

Black bar $=$ in the track biomass, Gray bar $=$ middle of the track biomass

Blackish bar $=$ out of the track biomass

Figure 9 shows the biomass differences inside, middle and outside of the track. (0) Grouping shows the not affected by surface sealing and (1) shows the affected area of sealing. Biomass in the (0) area outside track is higher then (1) area.

ii) Soil Texture and biomass

The linear regression model shows that there is significant relation of soil texture to the biomass (Table 5). However, ORD have impact on sandy soil (Figure 3). The biomass is lower in the sandy soil in all three situations: inside, middle and outside of the track. Clay loam soil has the highest biomass followed by sandy clay sandy loam and sandy soil.

Table 4. Regression Output Dependent Variable: Biomass

\begin{tabular}{|l|c|c|c|}
\hline \multicolumn{1}{|c|}{$\mathrm{R}^{\wedge} 2=000$} & Coefficients & $\mathrm{t}$ & Sig. \\
\hline (Constant) & 35.786 & 5.652 & .000 \\
\hline Soil texture & -.528 & -.379 & .705 \\
\hline
\end{tabular}

Model $y=a+b x$ therefore biomass $=35.786-0.528 *$ texture (sand, sandy loam, sandy clay, clay loam significant level is more than 0.05 , so the influence of soil texture is negligible.

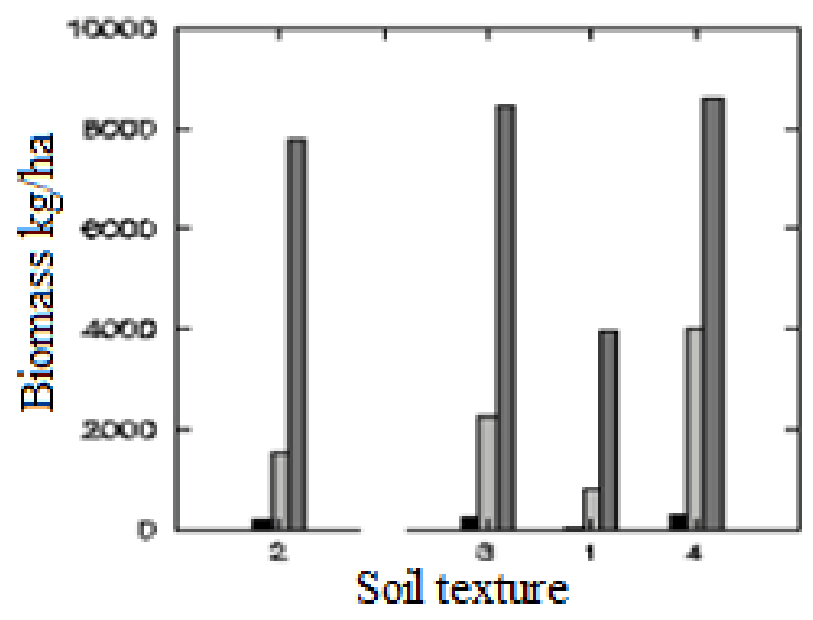

Figure 10. Influence of soil texture on biomass

Where $1=$ Sandy, $2=$ Sandy loam, $3=$ Sandy clay, $4=$ Clay loam, Black bar $=$ In the track, Grey bar $=$ Middle track, Blackish bar $=$ Out of the Track.

Figure shows the influence of soil texture on biomass distribution in the track, middle of the track and out of the track situation. In the sandy soil, biomass is lower in the out sidetrack but there is very strong impact of off the road driving on this soil type.

iii) Soil moisture on top and sub soil VS biomass.

Vegetation growth depends on the soil moisture. There is significant influence of sub soil moisture on biomass. In the off road track the moisture influence is not significant while out of the track the influence is significant. So, we can conclude that in the sub soil moisture has positive impact for the growth of biomass (Figure 11).

Figure 9 shows the influence of soil moisture on biomass,

Where $1=$ wet, $2=$ dry $\& 3=$ very dry. 


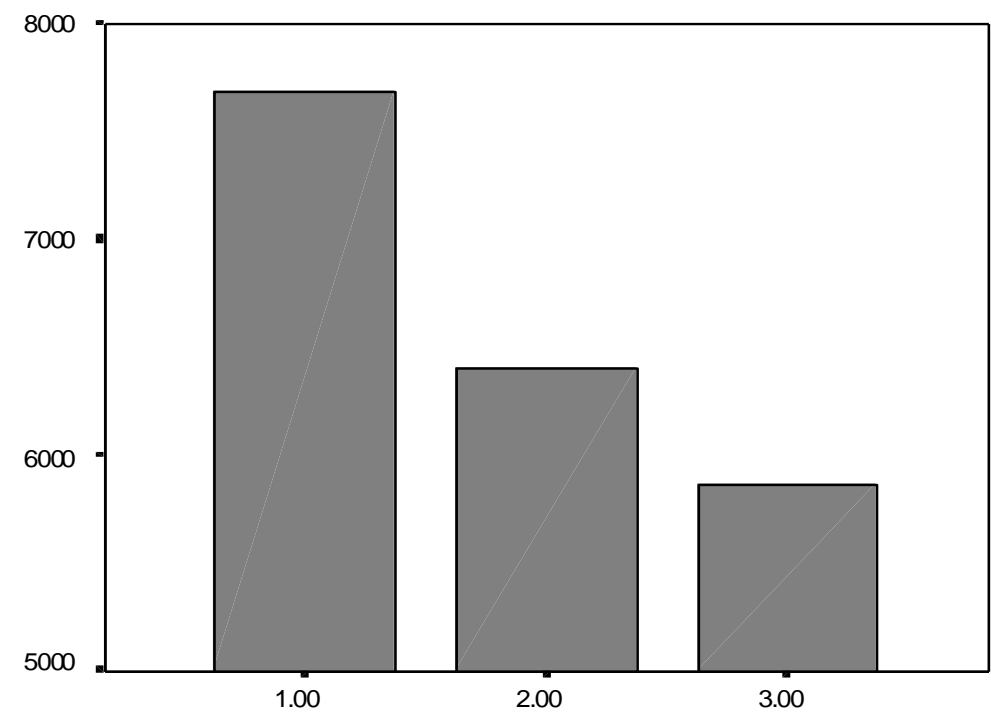

Soil moisture (Sub soil, out side track situation)

Figure 11. The influence of soil moisture on biomass

\section{Measurement of soil compaction}

The soil compaction is a major impact by the off-road driving. It is being caused by intensive use of off road recreational vehicles in the National Park. Compaction affects soil microstructure, which changes suitability of sites for seed germination (Harper and others 1965). Vehicle tracks, produced mainly by four-wheel vehicles and tourist minibuses, are very common in the park. Weighted vehicle's tire rolling outside the road affects vegetation immediately and the pressured area remains long time affected. To measure the soil compaction penetrometer was used.

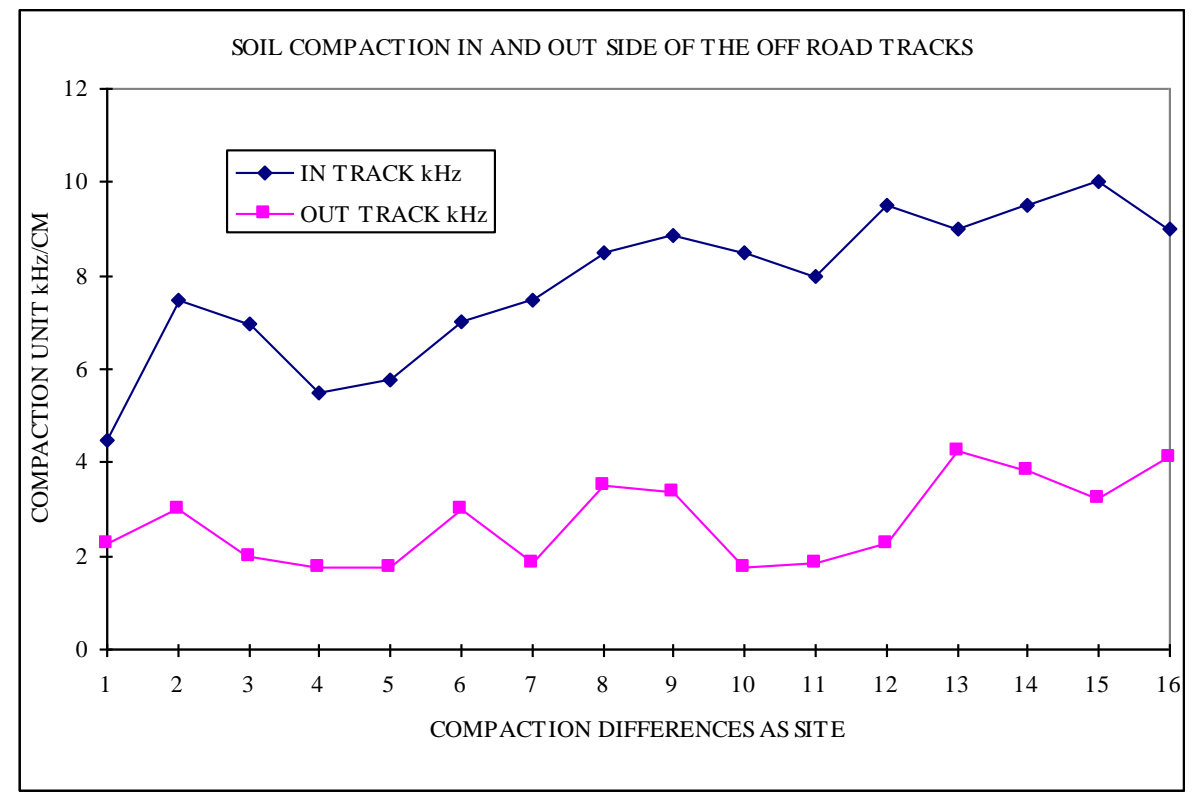

Figure 12. Soil compaction due to ORD- inside the track highly compacted

\section{Penetrometer test}

Penetrometer test is one of the techniques for characterising soil compaction in the field. What is measured is not soil strength per se, but a composite parameter considered to be related to soil strength, though the qualitative nature of its relation to soil strength is not known in exact sense (Hillel, 1980). As mentioned by Landon (1991: 100) penetrometer measurements in studies such as compaction studies are greatly influenced by size, shape and composition of the penetrating head, and above all, by soil moisture contents and operator variation. 
The results should therefore be used only to give rough comparative figures for similar situations, unless very careful standardization is ensured.

In this study penetrometer test was used to measure compaction/ penetration resistance for comparison of soil compaction in the off the road track, middle of the two tracks and areas where off road vehicles have no visible effect. Penetrometer was pushed in to the surface of the ground in the track, middle of the tracks and out of the track until the mark of penetrometer head was covered / entered and the pressure was read on the scale. After each reading the scale was moved back and this process was repeated five times in each type. In one sample site, 25 measurements were carried out. It was done equally in all sampling sites, see photo 1 (use of penetrometer) and Figure.

\section{Off road driving impact on soil compaction}

Another purpose of this study was to establish the reason behind why there was low vegetation recovery after the closure of ORD. It was hypothesised that soils, once compacted, recover extremely slowly. This would result in a long persistence of reduced infiltration rates.

Soil compaction was measured as soil resistance of the top layer. The impact of ORD was assessed comparing compaction on the track and compaction out of the track. Likewise, these two situations were compared between open area, areas of 1 year as well as 8 years of closure (see methodology). First of all, we tested the null hypothesis whether soil compaction was equal in and out side the track.

A paired t-test was used for the purpose. Let $d i$ be the difference in soil compaction between the plots in and outside the track at site i. We tested following hypothesis:

$H_{0}: \Delta=0$

$H_{A}: \Delta \neq 0$

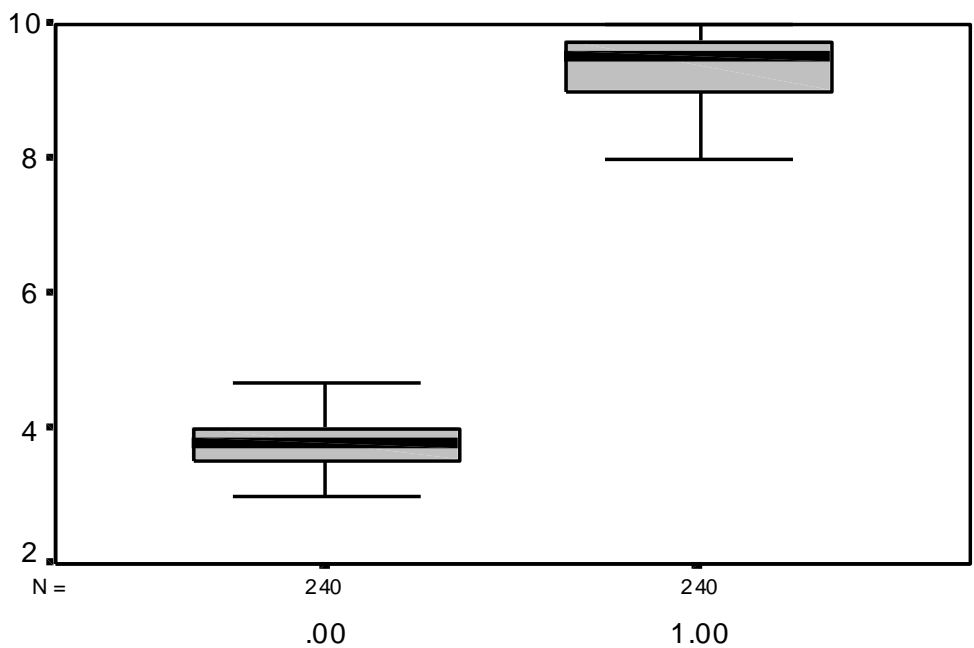

Out side the track and inside the track

Where $0=$ out side the track soil comapaction

and $1=$ inside the track soil compaction

Figure 13. Soil compaction variation

Where $\Delta$ is the population mean in soil compaction between tracks and areas outside the tracks. The test indicated that the difference in soil resistance between the track and the area outside the track, differed significantly from zero (paired t-test, $\mathrm{t}=118.4, \mathrm{~N}=480$ and $\mathrm{p}<0005$ ).

The areas in the track had a soil resistance, which was on average $5.55 \mathrm{~cm}$ higher than the areas outside the track. Figure revels the soil compaction inside the track and outside the track. Figure 11 shows the compaction differences between inside and out side the track, 
Where $0=$ outside the track and $1=$ inside the track soil compaction.

Next, we investigated whether there was an impact of management status on soil resistant.

We calculated the average pair wise differences in soil compaction between tracks and areas outside the tracks for the three management status categories $\left(d_{0}, d_{1}, d_{8}\right)$ where $0=$ open area, 1 and $8=$ to closed years respectively).

We than used ANOVA to test the following hypothesis:

$H_{0}: \Delta_{0}=\Delta_{1}=\Delta_{8}$

$H_{A}$ : at least one of these population means differs from the others.

The analysis revealed a significant difference in the pair wise differences in soil compaction (ANOVA; $\mathrm{N}=480$, $\mathrm{I}=3, \mathrm{~F}=8631.96$ and $\mathrm{P}<00005)$. Figure 4.4 shows that the difference in soil compaction between inside and outside the track and the closed areas for ORD. The rate of change however remains very low. After 8 years, soil compaction in the track still remains significantly higher than the compaction outside the track (pair t-test; $\mathrm{N}=480, \mathrm{t}=45.98$ and $\mathrm{p}<00005)$.

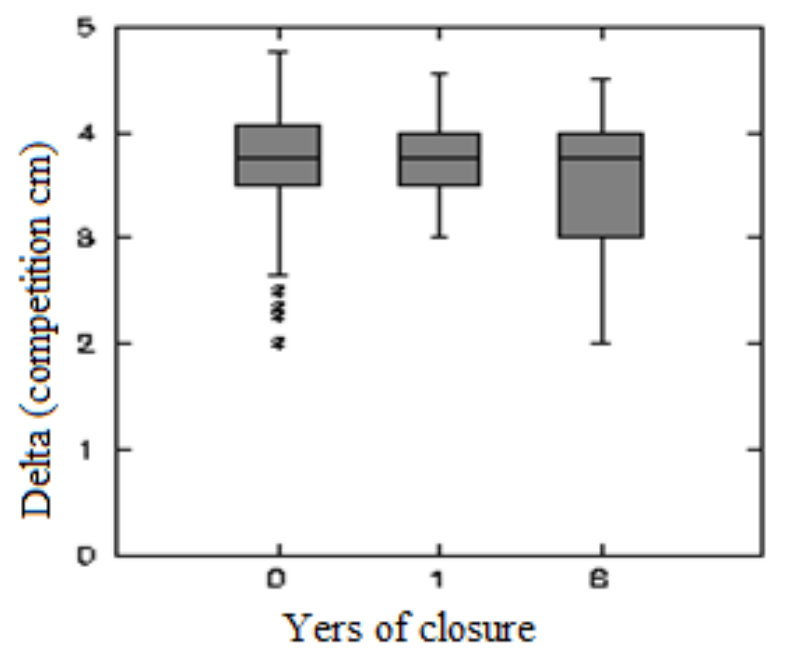

Figure 14. The influence of management on soil resistance

Figure 14 shows the soil resistance differences in the area 0 open area for ORD and 1 and 8 represents areas closed years respectively.

\section{Measurements of infiltration}

Soil compaction directly affects the water infiltration. Compacted soil does not allow infiltration and it affects vegetation.

\section{Infiltration test}

Infiltration rate of surface soil is important for determining the amount of water entering in the soil. The test was done to see the differences in soil strength between the tracks, middle of the tracks and out of the tracks. Iron infiltration rings were used to carry out infiltration measurements. Rings were pushed two centimetres in the soil correctly and adjusted to avoid the water loss by using a hammer. Five measurements were taken (Figure 15). In each site in the first track, middle of the tracks, in the second track and outside of both first and second tracks, infiltration rings were established. In each of the ring four centimetres of water was filled in and time was noted. Time was recorded every 5 minutes interval up to thirty minutes. 


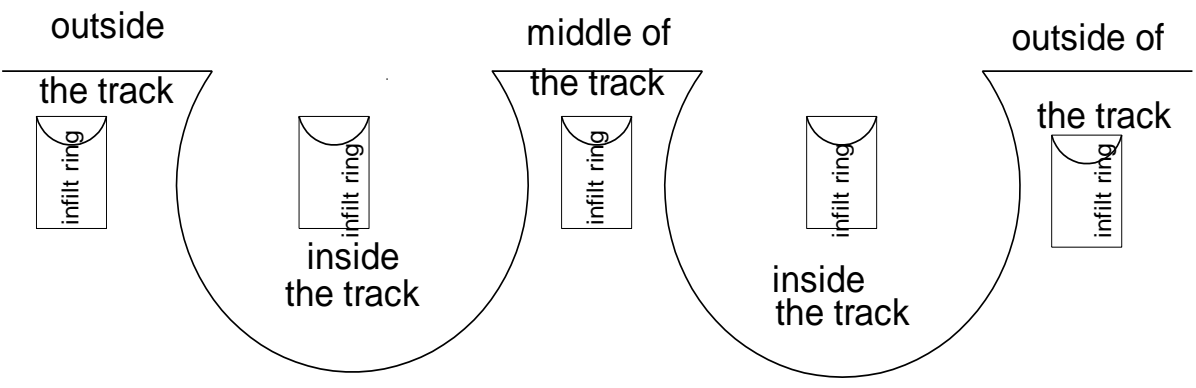

Figure 15. The way of infiltration measurements

Figure shows ring establishment in the sample plots.

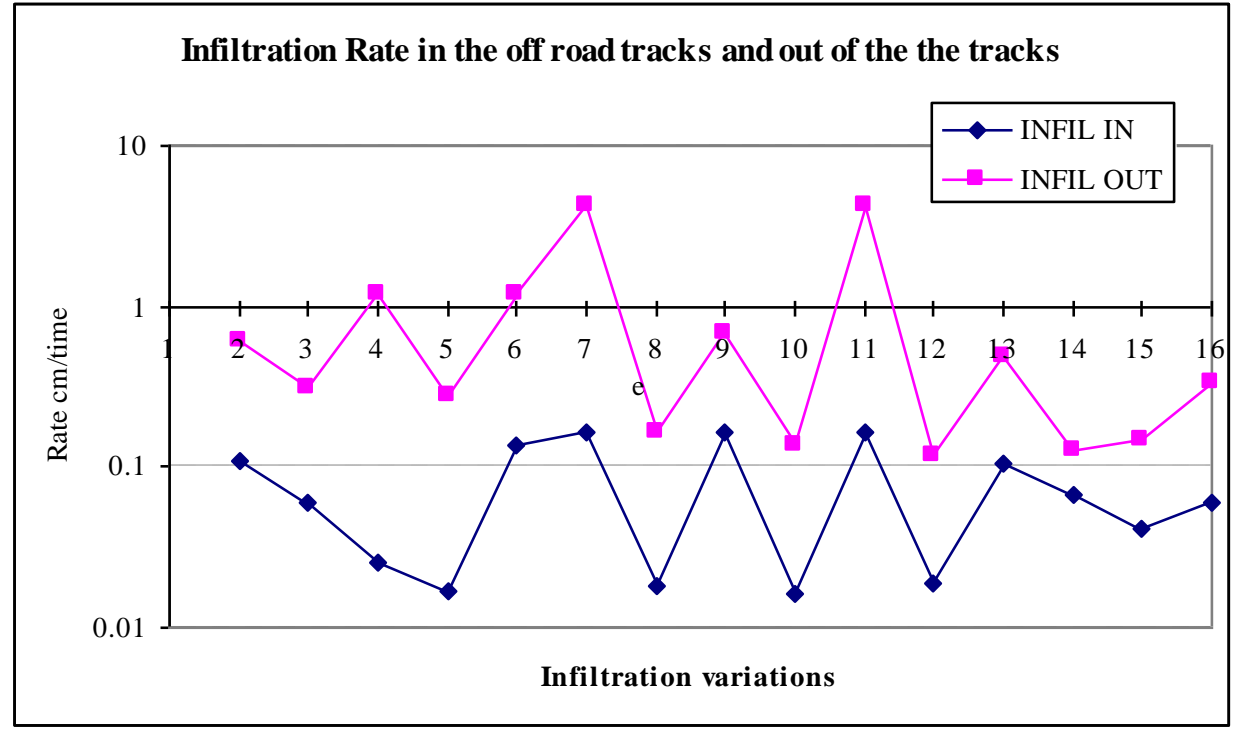

Figure 16. Infiltration variation inside the tracks and outside of the ORD tracks

Figure shows low infiltration inside the tracks and normal infiltration on the outside of the ORD tracks.

\section{Off road driving impact on infiltration}

One of the objectives of this study was to test whether infiltration of water was affected by ORD and conservation measures. Therefore, it was measured the rate of water infiltrated in soil at regular interval of 30 minutes. These data were then submitted to a forward multiple regression. Initially it was explored the non-linear relationship. However, quadratic and log transformation of the independent variable did not improve the curve fit over the linear model.

The full leaner model had the following form:

$Y=a+b_{1} * x_{1}+b_{2} * x_{2}+b_{3} * x_{3}+b_{4} * x_{4}$

Where, $x_{1}$ is the time in minutes since the start of the infiltration experiment, $x_{2}$ equals the place along the transects perpendicular to the track $(1=$ inside or $0=$ outside $), x_{3}$ represents the soil texture class and $x_{4}$ stands for the three management categories, open for traffic, and 1 or 8 years closed for ORD.

Figure 15 displays the original data and the predicted infiltration according to the regression model described above. The figure and results of the regression revels as expected one might have that the amount of water infiltrated is statistically significantly influenced by the soil texture and time since start of experiment (see appendix for detail model).

In addition, there is a significant impact of the position of the plots (in or outside the track, $\mathrm{t}=-43.9, \mathrm{p}<$ $0.0005)$ as well as the management status $(t=7.12, p<0.0005)$. The model explained $71 \%$ (Multiple $r=84$ and $\mathrm{r}^{\wedge} 2=71$ ) of the variance in water infiltrated in to the soil. Plots inside the tracks do have significantly lower infiltration rates than those outside the tracks (Figure 12). 
Closure of the plots to ORD results in a statistically significant increased of infiltration rate. The increase remains very low however $(0.046 \mathrm{~cm}$, per year of closure $)$ compared to the differences caused by the other factors.

On the base of the above figure and statistical analysis we can conclude that with consideration of soil and another unseen environmental factor infiltration is mainly affected by the off-road driving on the park. However, the areas are not same every where in the park, infiltration varies but in comparison with place to place infiltration in the track is very low. The closure area has higher infiltration than open area but the infiltration rate is still very low. Following figures gives a general overview of other factors influence on infiltration.
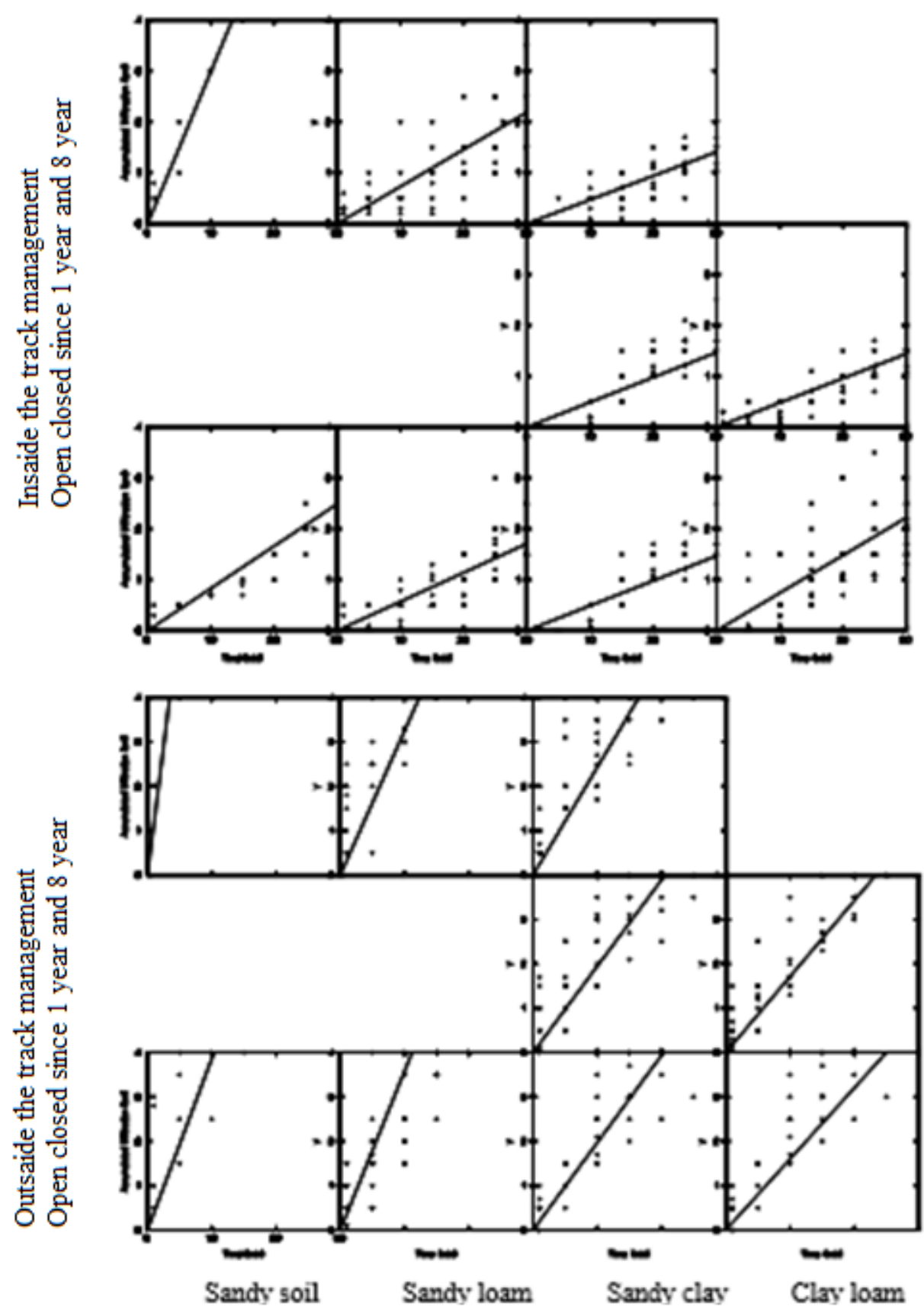

Figure 17. Regression graph of infiltration on different soil system

It depicts the relationship between the water infiltration lengths in three different situations open areas for offroad driving (where off-road driving is still occurring), areas closed for off-road driving since last year and the area off-road driving was closed since last eight years or so in Sandy, Sandy Loam, Sandy Clay and Clay Loam soil systems. 


\section{Soil Texture}

Figure 17 Accumulated amount of water infiltrated in to the soil $(\mathrm{cm})$ in relation to time since starts of the infiltration experiment (x-axis), soil texture (4 classes) management (open and $1 \& 8$-year closure respectively) and position of the plots. Where, the solid lines display the predicted infiltration according to the selected regression model.

\section{Conclusion}

The study revealed a statistically strongly significant impact of off road driving on the Masai Mara National Reserve and its adjoining areas. The impact of ORD on the vegetation biomass, vegetation cover percentage as well as species composition was tested using various statistical models. It was found that in the ORD affected areas vegetation biomass, vegetation cover percentage and species composition was significantly lower than in the surrounding. Likewise, soil compaction was significantly high and infiltration was significantly low.

Furthermore, the impact was not only significant inside the tracks but also in the middle of the tracks. However, the degree of impact in the middle of the track was less than that of inside the track.

In addition to the direct measurable impact on vegetation and soil, ORD has been also responsible for change in ecological condition of the area to some extent through succession. It was found that many plant species such as Themeda triandra, Dichanthium insanlpta, Sporobus pyramidalis, Dyschoristers redican, Digiteria longiflora, Pennesteum mezianum, Hypertheria dissoluta were very sensitive to ORD effects while species like Eragrostis tennifolia, Harpachne schimperi, Microchloa kuuthii, Cynodon dactylon, Eragrostis recamosa, Sporobus species and Cloris species were found to be most tolerant to such effects. The original soft grass species were replaced by hard grasses. The dominant species of the Mara ecosystem, Themeda triandra being very sensitive, was found to be replaced by other new emerging species like Eragrostis tennifolia, Harpachne schimperi and Microchloa kuuthii over time.

The ORD pressure on the Masai Mara is due to an abundance of all big five animals; the lion, cheetah, elephant, rhinoceros and wild buffaloes and other carnivore and herbivores such as hyenas, wildebeest, zebras, eland, topi, and different species of antelope and the Masai Mara ostrich as well as many other species. Another spectacle of the Masai Mara is the seasonal wildebeest migration from the Serengeti through the Masai area, which is one of the greatest events on Earth; millions of wildlife traveling at the same time followed by many predators. This brings many seasonal tourists to the Masai Mara Reserve. But expanded tourist facilities have caused the loss of wildlife habitat and naturalness of the area. The growing number of visitors has led to vehicle entries in the park and off-road driving for closer view of wild animals (Bhandari 2014).

\section{Recommendations}

Tourism is one of the main sources of foreign exchange in Kenya, which is also providing substantial benefits to the government and to the general public including employment and business. However, due to extreme pressure of tourists in a particular site, such as in the Masai Mara, natural habitats of wildlife are being degraded. To overcome the problem policies, need to be formulated and need to be implemented.

There is still need of further study on:

How ORD is affecting soil micro characteristics and exactly how long does it take to improve?

How much ORD and human interference has influenced the wildlife habitat?

What would be a sustainable tourist 'load' for alert management scenarios?

\section{Acknowledgement}

First of all, I would like to thank to International Institute for Aerospace Survey and Earth Sciences, Enschede, the Netherlands and the Netherlands Government, who provided funding to conduct this research as a master thesis, which actually helped to focus on the area. Since then I continually became involve on the issues not only in Kenyan issues but also to rest of the world. I would also like to thank to Dr. H. Gyde Lund, who publish our request for data on weekly online journal, Forest Information Update Vol. 6, No. 25, 20 June 2005, and Ms Agustina, Moderator, Mountain Forum Team, (www.mtnforum.org), who posted our request to the global and 
all sector of email list serve of mountain forum members. Several people from various countries responded and provided the information by email, which is used in this paper. I would like to thank to all of them.

Special thanks to Ms. Prajita Bhandari for her insightful comments, and input. I would also like to thank to Prameya, Manaslu and Kelsey, especially for their positive comments on the language pattern of this paper. I would also like to thank the reviewer panel for their input and comments.

\section{References}

1. Amuyunzu, C. (1984). Land resources inventory as a basis for Land Evaluation and Rural Development: The role of remote sensing techniques. Narok District, Kenya. M.Sc. Thesis, ITC, Enschede, The Netherlands.

2. Backcountry Hunters and Anglers (2004-2005). Off Road Vehicle Use http://www.backcountryhunters.org/index.php?link=orvs.

3. Baldwin, M. F. And D. Stoddard Jr. (1973). The Off-Road Vehicle and Environmental Quality, pp. 8-27. Second Edition. The Conservation Foundation, Washington, D.C., USA.

4. Baldwin, M. F. (1970). The Off-Road Vehicle and Environmental Quality: A report on the Social and Environmental Effects of Off-Road Vehicles, Particularly Snowmobiles, with Suggested Policies for their Control. Conservation Foundation. Washington, D.C., USA.

5. Belnap, J. (2002). Impacts of off-road vehicles on nitrogen cycles in biological soil crusts: resistance in different U.S. deserts. Journal of Arid Environments, 52, 155-165.

6. Bhandari, Medani P. (1998). Assessing the Impact of off road Driving in Masai Mara National Park, Narok, Kenya. M.Sc. Thesis, ITC, the Netherlands.

7. Bhandari, Medani P. (2014). Is Tourism Always Beneficial? A Case Study from Masai Mara, National Reserve, Narok, Kenya. Pacific Journal of Science and Technology, 15(1), 458-483.

8. Brander, R. B. (1971). Longevity of wild Porcupines, J. Mammal., 52, 835.

9. Bury, R. B. (1980). What we know and do not know about off-road vehicle impacts on Wildlife. R.N.L. Andrews and P. Nowak, editors. Off-Road Vehicle Use: A Management Challenge. (Univ. of Michigan Extension Service) Michigan League. The University of Michigan, School of Natural Resources. USDA The Office of Environmental Quality.

10. CBS (2000-2014). Central Bureau of Statistics of Kenya, Kenyalogy, Kenya Wildlife Service.

11. Davidson, Deb Kemon (2005). The Sound and Fury of National Forest Travel Planning Will the Future Be So Loud That You'll Need to Wear Earplugs in Our National Forests? American Wildlands, Montana. Conservation Environment (1988), 13. Available at: http://www.wildlands.org/foresttravel.html.

12. Forest info (2005). Forest Information Update, 6(25), 20 June 2005.

13. Georgia Forest watch Studies (2005). ORV Impact on Chattahoochee National Forest. Available at: http://www.gafw.org/orv_impact_study.htm.

14. Illinois Action Project (2001-2005). Off Road Vehicles Out of Control. Available at: http://www.illinoisactionproject.org/showalert.asp?aaid=308 July 20, 2005.

15. McCool, C. (1981). Catching wild livestock and feral animals-some of the problems. Northern Territory Division of Agriculture and Stock, Technical Bulletin No. 36.

16. Sawyer et al. (2005). Cumulative Effect Assessment On Alberta's Southern Eastern Slopes. Available at: http://72.14.207.104/search?q=cache:u2X0x16KqiMJ:www.hayduke.ca/science/effects.html+evidence+of+protected+area+damage+due+to+the+recreational+activities\&hl=en (downloaded July 11, 2005).

17. Sheridan, D. (1979). Off-road vehicles on public land. Council on Environmental Quality, U.S. Government Printing Office. Report No. 041-011-00041-6.

18. Siskiyou Wild Rivers Campaign, (2005). Off-road vehicles, Siskiyou Project. 917 SW Oak, Suite 407, Portland, OR 97205. Available at: http://www.siskiyou.org/swrc/threats/logging.cfm.

19. State Environmental Resource Center, Madison, Wisconsin- (2003). Available at: http://www.serconline.org/orv/talking.html.

20. Walpole et al. (2003). Wildlife and People: Conflict and Conservation in Masai Mara, Kenya. IIED, UK, and Mara Count Project 2002.

21. Walpole, M., Karanja, G.G., Sitati, N.W. and Leader-Williuams, N. (2003). Wildlife and People: Conflict and Conservation in Masai Mara, Kenya. Wildlife and Development Series No. 14, International Institute for Environment and Development: London, UK.

22. Walpole, M.J. and Leader-William, N. (2001). Masai Mara Tourism Reveals Partnership Benefits. Nature, 413: 771 (25 October 2001). doi:10.1038/35101762. 


\section{Appendix}
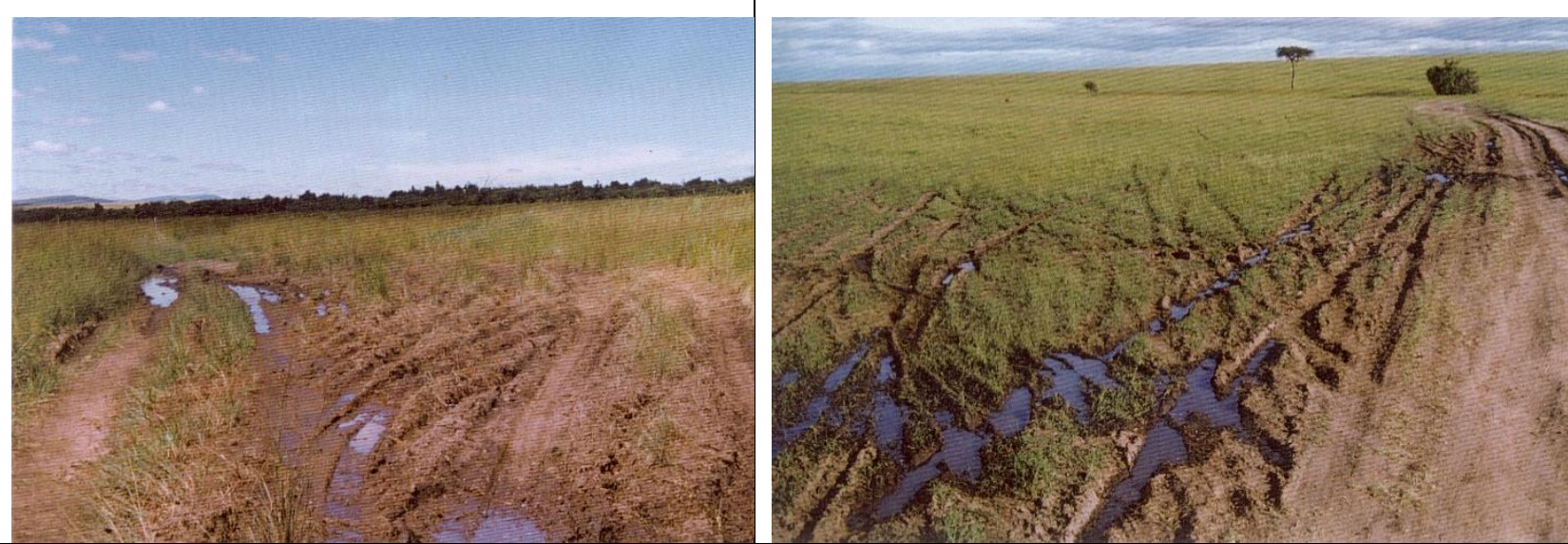

Photos 1 and 2 show the land damage by the off-road vehicles. Photos by author

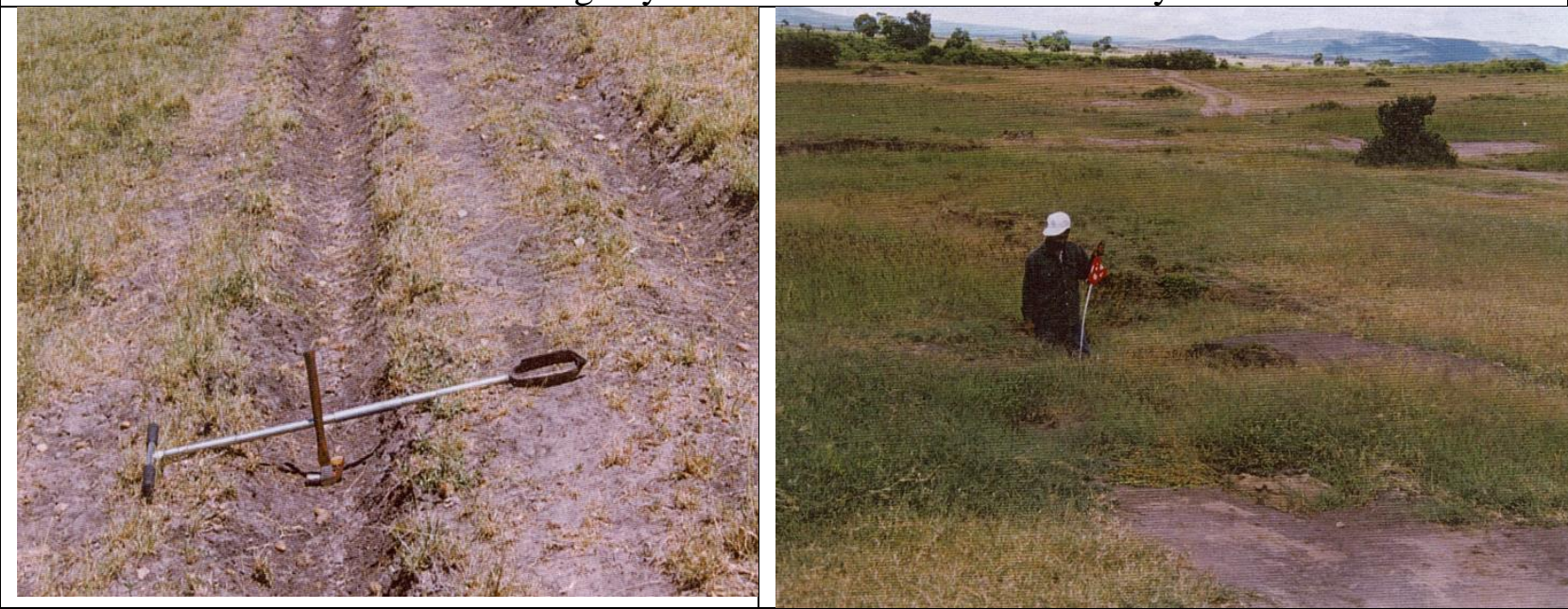

Photos 3 and 4 show off road driving tracks leading to soil erosion, author measures erosion gullies in the Masai Mara.

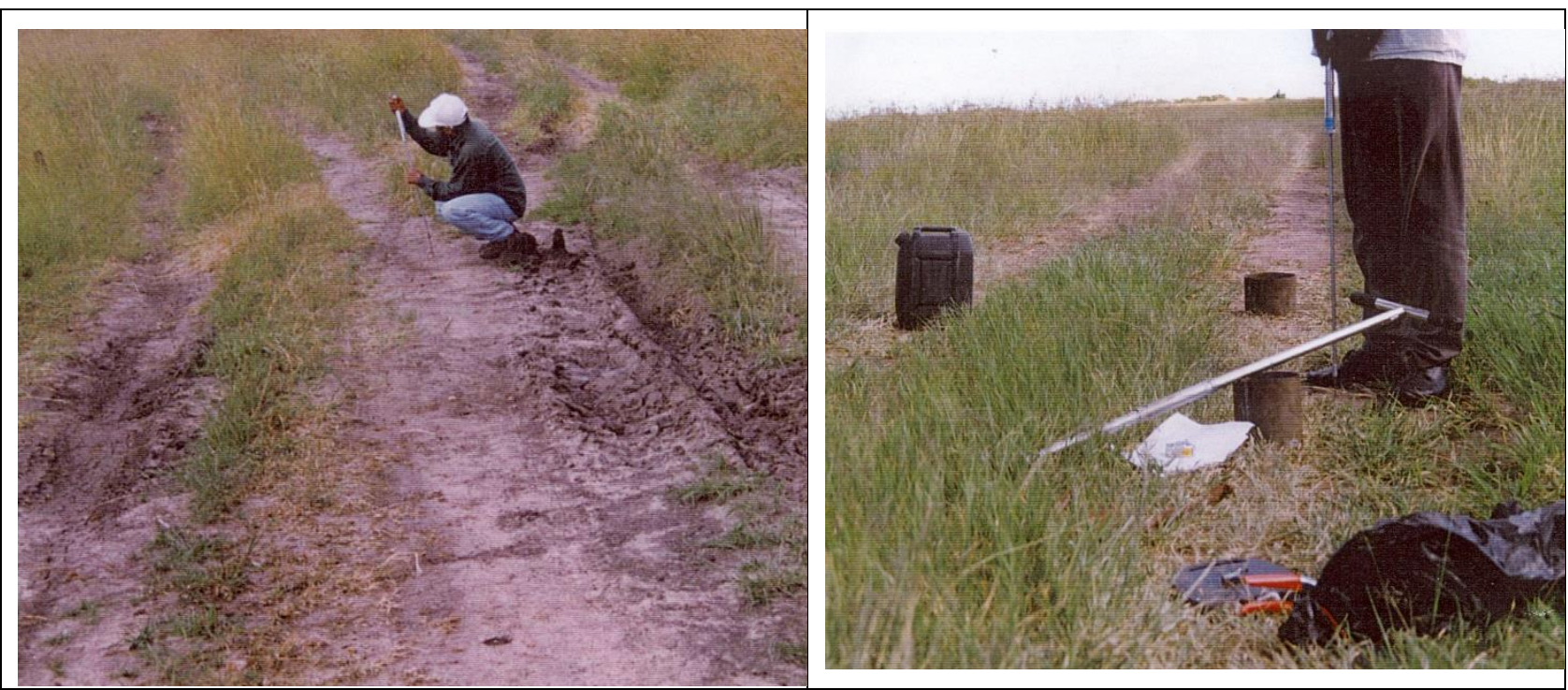

Photos 5 and 6 show the measurement of soil compaction. Medani Bhandari is measuring soil compaction inside the off-road tract (off road damaged area, where still off road is continue). 